\title{
Appointment systems: evaluation of a flexible system offering patients limited choice
}

\author{
A T HARRISON
}

\begin{abstract}
To test the efficiency of a flexible appointments system patients seeing one of the partners in a semirural dispensing practice were asked to choose whether they wanted appointments lasting five, 10 , or 15 minutes. After seeing the doctor they were asked to fill in a questionnaire that asked, among other questions, how long an appointment they had booked, whether they had felt rushed, whether the doctor had seemed hurried, whether they had seen the doctor on the day they wanted, how long they had had to wait in the surgery, and whether they liked the system. Five minute appointments had been chosen by 124 of the 309 patients who returned completed questionnaires, 10 minute appointments by 155 , and 15 minute appointments by 30 . Mean consultation times were $6 \cdot 1,9 \cdot 2$, and 12.9 minutes, respectively. Altogether 298 patients liked the system.

An appointment system that was flexible while remaining practical and efficient resulted from letting patients choose the length of their appointment. Such a system encourages patients to share in the responsibility of organising a practice efficiently.
\end{abstract}

\section{Introduction}

Over $70 \%$ of practices now use appointment systems. ${ }^{1}$ Most doctors choose five or 10 minutes or some fixed time between these for booking consultations. Such systems are rarely flexible and therefore fail to reflect the unpredictable nature of a general practitioner's

Medical Centre, East Bridgford, Nottingham NG13 8NH

A T HARRISON, MRCP', MRCGP, general practitioner trainer work. Accommodating the considerable variation in time taken for consultations during an average surgery requires knowledge of the problems to be addressed and a flexible system.

I had found previously that patients could estimate how long they required with the doctor sufficiently accurately that a feasible alternative to traditional appointment systems could be set up. ${ }^{2}$ There were, however, practical difficulties in allocating irregular periods of time. In an effort to retain the element of choice for patients in a system that was easier to administer I offered patients in the present study a choice of five, 10 , or 15 minute appointments. I assessed the appropriateness of their choice, the efficiency of the resulting system, and patients' reactions to the system.

\section{Methods}

About 5100 patients attend this semirural practice, which operates a system of personal lists for one part time and two full time partners. Patients making an appointment to see me were asked if they required a five, 10 , or 15 minute appointment. The appointment book was altered so that one, two, or three slots of five minutes could be allocated to the patient as requested. Appointments began at $830 \mathrm{am}$, and whenever possible patients were booked in on the day of their choosing. All patients who said that their problem was urgent were seen on the same day; surgery hours were extended if required. When I knew that patients would be returning during the trial period I advised them how long an appointment to book. A run in period of two months was allowed so that reception staff could familiarise themselves with the system. The trial lasted for one month.

At the start of each surgery I was given a list of names in the order that they were booked but with no indication of how much time had been allocated to each or when the surgery was scheduled to finish. Every consultation was timed; included was the time spent filling in forms, making entries in the records, and dealing with interruptions such as telephone calls from other doctors or from patients requesting visits. Opportunities for preventive medicine and health education were dealt with according to usual practice.

At the end of the consultation patients were given a questionnaire asking how long an appointment they had booked; if they had previously been 
advised how long to book; if they had felt rushed or the doctor had seemed hurried in the consultation; if they were aware how long they had normally been allocated in the previous appointment system; whether they had got an appointment on the day they requested and if not how long they had waited; if they had been seen at the appointed time and if not how long they had waited; and whether they liked the system. They were asked to leave the questionnaire in a box in the waiting area and were told that it was anonymous. I noted any waiting time between patients. I did not assess the content of the consultation.

\section{Results}

The questionnaire was given to 339 consecutive patients; 309 questionnaires that had been correctly filled in were left in the box provided. Table I shows the replies to each question.

TABLE I-Responses to questionnaire on length of appointment

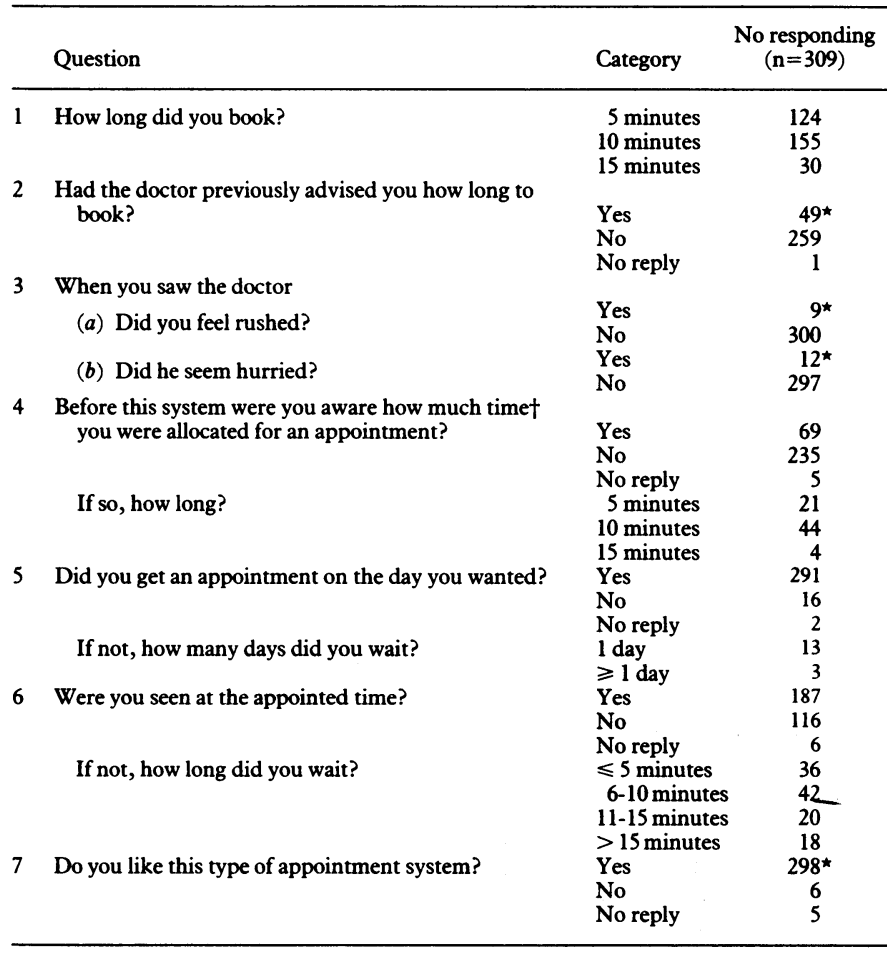

*No significant difference $\left(\chi^{2}\right.$ test) among groups booking five, 10, and 15 minute appointments.

†Previous system had 10 minute appointments.

The three groups of patients requesting five, 10 , and 15 minute appointments showed no significant differences in their responses to whether they felt rushed, whether the doctor seemed hurried, whether they liked the system, whether they had been advised how long they would require, and how long it had taken to get an appointment. Forty four of the 69 patients who said that they knew how long they had been allocated in the previous system correctly said 10 minutes. Of those who were wrong, 21 thought that they had normally been allocated five minutes. Most of these 21 patients had booked five minute appointments in the new system, and the mean actual duration of their consultation was the same as that of all 124 patients who requested five minute appointments $(6 \cdot 1$ minutes). Table II

TABLE II-Comparison of length of appointment chosen and actual time taken

\begin{tabular}{lccc}
\hline $\begin{array}{l}\text { Time booked } \\
\text { (minutes) }\end{array}$ & $\begin{array}{c}\text { No of } \\
\text { patients }\end{array}$ & $\begin{array}{c}\text { Mean (SD) time } \\
\text { taken (minutes) }\end{array}$ & $\begin{array}{c}\text { Range } \\
\text { (minutes) }\end{array}$ \\
\hline 5 & 124 & $6 \cdot 13(2 \cdot 52)$ & $2-15$ \\
10 & 155 & $9 \cdot 20(3 \cdot 45)$ & $2-21$ \\
15 & 30 & $12 \cdot 93(5 \cdot 15)$ & $5 \cdot 5-27$ \\
\hline
\end{tabular}

$\star$ Not significant, $\chi^{2}$ test. shows the mean duration of appointments of patients opting for five, 10, and 15 minute appointments. There was no significant difference between actual and estimated times for each group.

I recorded that I waited 74 minutes between patients during the whole trial, an average of 13 seconds per patient (three minutes for every 15 patients seen). The overall time spent on consultations was 15-16 hours a week in eight sessions. This was similar to the time allocated for appointments 10 minutes long in the previous appointment system.

\section{Discussion}

The results show that patients were able to indicate appropriately their requirements for five, 10 , or 15 minute appointments. The system that resulted was efficient: the average waiting time (about four minutes) was acceptable to patients, few patients had to wait more than 15 minutes, and the waiting time for the doctor was minimal. Choice of appointment lengths has been tested twice in this practice, and there seems little doubt that patients can predict how much of the doctor's time they require sufficiently accurately to contribute to an efficient system. ${ }^{2}$ Limiting their choice to three lengths of appointment eased practical difficulties and did not adversely affect efficiency.

The major part of a general practitioner's work is consultation in the surgery. Any system that attempts to predict the duration of appointments or ration the number of consultations is of fundamental importance to this work. An inefficient or unrealistic appointment system may influence the content of a consultation when the doctor is aware that other patients are being kept waiting. Longer consultations have been found to increase patients' satisfaction and to include more preventive medicine and health education. ${ }^{34}$

Limitless time is not, however, available, and not everyone wants or needs a 10 minute appointment. Efficiency in a system is not difficult to obtain, as shown elsewhere. ${ }^{56}$ Efficiency combined with opportunities for a high standard of health care within the constraints of time available is the goal.

A flexible system with an element of choice for patients offers an opportunity to respond to their needs according to their own perceptions of these needs. This requires cooperation and some measure of insight from the patients. When we ask patients to follow advice and comply with treatment we ask them to accept responsibility for aspects of their health care. Some practices go further by setting up patient participation groups or allowing direct access to records. The appointment system in this trial asked patients to share in the responsibility of organising the practice effectively by estimating how much of the doctor's time their problems would require. The resulting system reflects the efforts not of a motivated or articulate minority of patients but of a cross section of the population of the practice.

General practitioners are asked to be accessible and available yet to remain attentive and considerate as expectations for good health increase in the general population. The resultant pressures can adversely affect performance. Asking for cooperation in how we apportion our time and trusting patients to use their own judgment may contribute to better understanding and more appropriate use of services.

I thank Mrs S Jones (department of general practice, Medical School, University of Nottingham) for help with processing the results and Mrs S Fletcher for typing the manuscript.

\section{References}

1 Drury VM. Premises and organisation. In: Fry J, ed. Trends in general practice. London: British Medical Association, 1977:142-7.

2 Harrison AT. Appointment systems: feasibility study of a new approach. $\mathrm{Br}$ Med $\mathcal{F}$ 1987;294: 1465-6.

3 Morrell DC, Evans ME, Morris RW, Roland MO. The five minute consultation: effect of time constraint on clinical content and patient satisfaction. Br Med $\mathcal{J}$ 1986;292:870-3.

4 Roland MO, Bartholomew J, Courtenay MJF, Morris RW, Morrell DC. The five minute consultation: effect of time constraint on verbal communication. Br Med f 1986;292:874-6.

5 Marshall EI. Waiting for the doctor. Br Med F 1986;292:993-5.

6 Worrall G. Assessing an appointment system. $\mathcal{F}$ R Coll Gen Pract 1974;24:876-9.

7 Mayou R. Burn out. Br Med F 1987;295:284-5.

(Accepted 16 December 1987) 